\title{
Decision making model under the emission trading system in China and its implications
}

\author{
Xiaomei Guo, a , Li Huang, 2,b \\ ${ }^{1}$ Study center of Management Accounting, School of Management, Xiamen University ,P.R.China, \\ ${ }^{2}$ Tax Bureau of Jiasu Industrial Park, Jaing Su, P.R.China \\ aydxmguo@tom.com, bhuanglilily_2007@163.com
}

Keywords: Tradable allowance system; decision model; environmental cost; carbon emission.

Abstract. Currently, the tradable allowance system, which is a market based environmental policy, is being introduced in China. Under this system, enterprises are given much flexibility in decision making. In this article, the authors constructed decision strategies and models for enterprises and analyzed the condition for optimum solution, hoping to give some insights in the design of the system.

\section{Introduction}

Though the Chinese environmental protection bureau has put forward market based instrument for environmental conservation ever since 2008, it seems that it is the command and control that is prevalent, not the market based ones[1]. In theory, the tradable permit system is a market based instrument $[1,2]$ that will minimize the aggregate cost of achieving a given level of environmental protection. Though the cap and trade system was introduced to China since 1989. In 2007,pilot projects for the allowance trading system were approved by the central government to control carbon emission, with some experience gained. However, trading was not active[3]. In 2014, a guideline was published by the State Council of China, signaling the determination of the government to push forward the system nationwide after 2017[4].

The philosophy of tradable permit is that when emitter with higher control cost of pollution control will choose to buy permits from emitters with lower control cost, the former will have greater emission while the latter will have less emission, but total emission will remain unchanged. The system is so set that when environmental abatement cost varies, emitters will lower control cost have the option to reduce emission, and sell surplus allowance and save it for future uses. Emitters also have the option to buy, have the abatement technology, control emission with current technology or with innovated new technology. Many authors have discussed the experiences and the benefits of such system. Some also discuss the possible reaction of the emitters [5]. In this article, the authors set up a decision model for emitters and discuss the optimum solution of such model under different conditions, so that the reactions of the emitters can be better understood and a better light can be shed when the regulators design and launch the system in China. It will help the firms to make better decision to enforce their competitiveness.

The remaining section of the article is structured as followed, firstly a discussion of the strategic options, then the assumptions and the basic model are built, an analysis of the equilibrium points under differ options are made, and finally, conclusions and recommendations.

\section{Strategic options under the emission trading system}

Under the emission trading system, emission control is not an enforcement result of "command and control", but rather a result of the emitters' own choice. Utilities should make decision on whether to buy permits or to invest in pollutant treatment equipment. Depending on various variables, the firm will make the decision to the best of its interest.

Based on the design of the current emission trading system in China, throughout the problem of pollution control is assumed as such: there is a set of industrial sources of pollution owned by $\mathrm{N}$ risk neutral, profit-maximizing firms in a certain region, which is administrated under an emission trading 
system, wherein the government set the cap of emission at $\mathrm{M}$ based on some criterion. The government allocated a certain number $\left(\mathrm{R}_{0}\right)$ of permits to each of the firm in the region, which will become the suppliers and demanders of the permits in that region. For each of the firm, number of initial permits $\mathrm{R}_{0}$ and the price of the permits $\mathrm{P}_{0}$ are exogenous, i.e. The number of initial permits and its price remain constant.

Each of the firm is independent and makes the decision based on the goal of profit maximization. The emission system is designed in such a way so that when a shortage of permits exists, the firm has several choices. It can choose to abate pollutant emission though treatment by itself, or it can choose to adjust its output to keep its actual emission under the limit of permits it holds, or to buy permits from other firms. However, the trade off is dependent on the economics of inputs and outputs. Generally speaking, there are three compliance options that a firm can choose under different conditions, as shown in Table1.

Table 1 options of emitters under different conditions

\begin{tabular}{|l|l|l|l|}
\hline \multicolumn{2}{|c|}{ Conditions } & \multicolumn{1}{c|}{ option } & \multicolumn{1}{c|}{ possible actions } \\
\hline When output is adjustable & & Option1 & Control actual emission \\
\hline $\begin{array}{l}\text { When output is } \\
\text { unadjustable }\end{array}$ & Technology innovation & Option2 & Sell of excess permits \\
\cline { 2 - 4 } & At Current technology level & Option3 & Buy or sell permits \\
\hline
\end{tabular}

\section{Assumptions and basic model}

To find out the equilibrium point of the actions for different options, some assumptions are made as followed.

Assumption 1 Let $\mathrm{R}$ be the firm's number of permits necessary for actual emissions ${ }^{1}, \mathrm{Y}$ be the output of the firm. $\mathrm{R}$ is the monotonically increasing function of $\mathrm{Y}$, i.e. $\mathrm{R}$ is positively relative with $\mathrm{Y}$, denoted $\mathrm{R}(\mathrm{Y})$.

Assumption 2 Let $\mathrm{C}$ be firm's abatement cost, $\mathrm{Q}$ be the volume of controllable emission, emission that can be abated by treatment. Abatement cost, the function of Q, is denoted C (Q). Normally; due to effect of economies of scale, the greater the volume of controllable emission, the less the unit abatement cost. When volume of emission remains constant, increase in the emission abated causes cost to increase greatly. So, it the firm does not invest in pollution control technology, marginal abatement cost is strictly decreasing and convex in the firm' $s$ emissions $Q$, that is $C^{\prime}(Q)>0, C^{\prime \prime}$

( $Q) \geq 0[6]$.If the firm invests in technology, marginal abatement cost will be decreasing, i.e $\mathrm{C}^{\prime}(\mathrm{Q})>0, \mathrm{C}^{\prime \prime}(\mathrm{Q}) \leq 0$.

Assumption 3 Normally, when a firm`s actual emission goes beyond limit allowed, a fine will be imposed on the firm by the government. Let $\mathrm{G}$ be the fine imposed, and $\mathrm{V}$ be the excessive emission $^{2} \cdot G$ is a function of $V$, denoted $G(V) \cdot G(V)$ is increasing in $V . G^{\prime}>0, G^{\prime \prime} \geq 0$. When $\mathrm{V} \leq 0, \mathrm{G}(\mathrm{V})=0$.

Assumption 4 Let $\mathrm{X}$ be the shortage in emission permits for a firm, hence the quantity of permits traded, transaction cost be denoted $\mathrm{T}(\mathrm{X}), \mathrm{T}(\mathrm{X})$ is the monotonically increasing function of $\mathrm{X}$, marginal cost is decreasing.ie. $T^{\prime}(X)>0, T^{\prime \prime}(X) \leq 0$ [7].

From the design of the tradable allowance system, assumptions 1 and 2 , it can be seen that the initial emission is $\mathrm{R}_{0}$, actual emission, or staus quo emission, is $\mathrm{R}$, emission to be abated by pollution treatment is $Q$. Let $X$ denote the shortage of permits, $X=R-R_{0}-Q$. When $X<0$, the firm will be the seller of permits, when $X>0$, the firm will be purchaser of the permits.

Each firm makes decision based on profit maximization, so when there is a shortage of permits, the firm will decide on whether to reduce actual emission by pollutant treatment, to lower output to

\footnotetext{
${ }^{1}$ as each firm is required to hold an emissions permits for each of unit of emission it release, $\mathrm{R}$ represents the actual level of emission

${ }^{2}$ the difference between actual emission and the standards as shown in the permits.
} 
reduce emission, or the buy permits in the market completely on the criterion of the conditions of economics. Output is restricted by permits it holds.

Let $\mathrm{L}$ be price of the product which is assumed to be constant, when output is $\mathrm{Y}$, then revenue can be denoted as LY while $\mathrm{C}(\mathrm{Y})$ is the production cost function. Normally, profit function of the firm, not considering the environmental cost of pollution, is defined as

$$
\mathrm{E}=\mathrm{LY}-\mathrm{C}(\mathrm{Y})
$$

Based on assumption 1, As $\mathrm{R}$ and $\mathrm{Y}$ is positive relative, then $\mathrm{R}$ is a strictly concave function of $\mathrm{E}$, i.e. $E^{\prime}(R)>0, E^{\prime \prime}(R) \leq 0$. As such, total environmental cost $E C$ consists of cost for reducing pollution, cost for emission control, abatement cost, purchase cost of permits bought, transaction cost and penalty, i.e. $\mathrm{EC}=\mathrm{C}(\mathrm{Q})+\mathrm{P}_{0}(\mathrm{X}-\mathrm{V})+\mathrm{T}(\mathrm{X}-\mathrm{V})+\mathrm{G}(\mathrm{V})$

Among which, the abatement cost differs from firm to firm, while the purchase price of permits is determined by the permits market, transaction cost and penalty is determined by the design of the emission allowance system. Considering environmental cost, profit function is revised as

$$
\mathrm{E}=\mathrm{LY}-\mathrm{C}(\mathrm{Y})-\mathrm{EC}
$$

Maximization of the profit is written as:

$$
\operatorname{MaxE}=\mathrm{E}(\mathrm{R})-\mathrm{C}(\mathrm{Q})-\mathrm{P}_{0}(\mathrm{X}-\mathrm{V})-\mathrm{T}(\mathrm{X}-\mathrm{V})-\mathrm{G}(\mathrm{V})
$$

Normally, an audit will be carried out on polluters, and an effective allowance system is built on strict enforcement of monitor and penalty. So, as shown in assumption 3, usually equals to zero, ie. non compliance will not exist. So equation 2 can be simplified as

$$
\operatorname{MaxE}=E(R)-C(Q)-P_{0} X-T(X)=E(R)-C(Q)-P_{0}\left(R-R_{0}-Q\right)-T(X)
$$

\section{Decisions under different options}

Further analysis of the equilibrium model for three options mentioned above is as followed.

For option 1, as output is adjustable based on a firm's price and cost of output, the firm must adopt an emission level and adjusts its output in order to obtain maximum profit for the fixed level of emission. Optimum solution for equation ( 3$)$ is :

$$
\frac{\partial E(R)}{\partial R}=\frac{\partial\left[C(Q)+P_{0}\left(R-R_{0}-Q\right)+T(X)\right]}{\partial R}=P_{0}+\frac{d T(X)}{d X} \frac{\partial X}{\partial R}+\frac{d C(Q)}{d Q} \text {, ie: } \quad \frac{\partial E(R)}{\partial R}=\frac{\partial C}{\partial R}
$$

Profit maximization is achieved when marginal revenue equals marginal cost.

When output is not adjustable, the actual emission is not adjustable either. So demand for permits $\mathrm{R}$ will remain constant. Under this condition, the problem of efficient emission is to minimize EC, denoted as

$$
\operatorname{MinEC}=\mathrm{C}(\mathrm{Q})+\mathrm{P}_{0}\left(\mathrm{R}-\mathrm{R}_{0^{-}} \mathrm{Q}\right)+\mathrm{T}(\mathrm{X})
$$

s.t. $\mathrm{Q} \geq 0^{3}$, the Kuhn-Tucker condition is :

$$
\frac{\partial C(Q)}{\partial Q}-P_{0}+\frac{\partial T(|X|)}{\partial Q} \geq 0
$$

ie: when $\mathrm{Q}>0, \frac{\partial C(Q)}{\partial Q}=P_{0}-T(|X|) \frac{\partial|X|}{\partial Q}$; when $\mathrm{Q}=0, \frac{\partial C(Q)}{\partial Q} \succ P_{0}-T(|X|) \frac{\partial|X|}{\partial Q}$

When $\mathrm{Q}=0$,ie. abated emission is zero, the marginal environmental cost is greater than marginal purchase price or sales price of permits, so aggregated environmental cost is minimized when the firm

\footnotetext{
${ }^{3}$ From Assumption, let reduction in emission be $\mathrm{Q}, \mathrm{Q} \geq 0$.
} 
keeps the emission at current level. If there is shortage of permits hold, i.e. $X=R-R_{0}>0$, the firm will buy permits in the market, aggregated environmental cost will is $\mathrm{P}_{0} \mathrm{X}+\mathrm{T}(\mathrm{X})$.

When $\mathrm{Q}>0$, there are two possibilities.

If $\mathrm{X}>0$, the firm will choose to buy permits, aggregated environmental cost is minimized when marginal environmental cost equals to the sum of purchase cost and transaction cost ie. $\frac{\partial C(Q)}{\partial Q}=P_{0}+T^{\prime}(X)$.

If $X<0$, the firm will choose to sell permits, aggregated environmental cost is minimized when marginal environmental cost equals to the difference between purchase cost and transaction cost ie. $\frac{\partial C(Q)}{\partial Q}=P_{0}-T^{\prime}(X)$, the firm have excessive gains from sale of permits.

For a firm, an equilibrium exists when decides on whether to invest in technology to reduce its emission or to buy or sale its permits in the market.

For option 2, when the firm introduces new technology to control emission, due to economics of scale, marginal abatement cost will decrease, which makes it lower than the industrial average of marginal abatement cost. If transaction cost exists, the market transaction costs will increase with volume of transaction, yet the marginal transaction will decrease. There is an equilibrium treated emission $Q^{*}$, which is minimum equilibrium scale of economics of pollution control of the firm.

When $\mathrm{Q}<\mathrm{Q}^{*}$, it is not economic for the firm to control pollution, so firm will buy permits in the market. When $Q>Q^{*}$,number of permits that can be sold is $Q^{*} Q^{*}, E C=C(Q)+T\left(Q-Q^{*}\right)-P_{0}\left(Q-Q^{*}\right)$.

So $\mathrm{Q}^{*}$ is the equilibrium abated emission ,only when the abated emission level is at $\mathrm{Q}^{*}$ will firm choose to invest in pollution control technology.

For option 3 , firm treats pollution under current technology. Unit abatement cost increase as of actual emission increases, and the marginal cost increase too. The same is true for transaction cost, which increase in total as transaction volume increases, while marginal cost decreases.

Let $\mathrm{Q}_{2}{ }^{* *}$ represents the treated emission, $\mathrm{Q}_{1}{ }^{* *}$ represents the abated emission. Then marginal cost for a buyer is $\frac{\partial C(Q)}{\partial Q}=P_{0}+T^{\prime}(X)$, marginal cost for a seller is $\frac{\partial C(Q)}{\partial Q}=P_{0}-T^{\prime}(X)$. Only when marginal transaction cost is zero, will equilibrium point of the buyer be the same as the equilibrium point of the seller, and the abated emission is $\mathrm{Q}^{* *}$.In this case, marginal cost for both the buyers and sellers equals to the market equilibrium price of permits. As shown in assumption 4, transaction cost is not zero.

When shortage of permits is less than $\mathrm{Q}_{1}{ }^{* *}$, ie. $\mathrm{R}-\mathrm{R}_{0}<\mathrm{Q}_{1}{ }^{* *}$, the optimum abated emission is $\mathrm{Q}_{1}{ }^{* *}$, in addition to those necessary for actual emission, the firm has excess number of permits available for sold , which is $\mathrm{Q}_{1}{ }^{* *}-\mathrm{R}+\mathrm{R}_{0}$, Then $\mathrm{EC}=\mathrm{C}\left(\mathrm{Q}_{1}{ }^{* *}\right)-\mathrm{P}_{0}\left(\mathrm{Q}_{1}{ }^{* *}-\mathrm{R}+\mathrm{R}_{0}\right)+\mathrm{T}\left(\mathrm{Q}_{1}{ }^{* *}-\mathrm{R}+\mathrm{R}_{0}\right)$.

When $\mathrm{R}-\mathrm{R}_{0}>\mathrm{Q}_{2}{ }^{* *}$, the optimum abated emission is $\mathrm{Q}_{2}{ }^{* *}$, to cover the shortage for number of permits necessary for actual emission, the firm choose to buy permits in the market. The number of permits bought is $\mathrm{R}-\mathrm{R}_{0}-\mathrm{Q}_{2}{ }^{* *}, \mathrm{EC}=\mathrm{C}\left(\mathrm{Q}_{2}{ }^{* * *}\right)+\mathrm{P}_{0}\left(\mathrm{R}-\mathrm{R}_{0}-\mathrm{Q}_{2}{ }^{* * *}\right)+\mathrm{T}\left(\mathrm{R}-\mathrm{R}_{0}-\mathrm{Q}_{2}{ }^{* * *}\right)$.

When $\mathrm{Q}_{1}{ }^{*}<\mathrm{R}-\mathrm{R}_{0}<\mathrm{Q}_{2}{ }^{*}$, the revenue from sell of the permits will not be enough to cover the transaction cost, so firm should choose to reduce emission to be in compliance with the target set by the permits it holds.i.e. $\Delta \mathrm{Q}=\mathrm{R}-\mathrm{R}_{0} . \mathrm{EC}=\mathrm{C}(\Delta \mathrm{Q})$. 
Table 2 Decisions and the equilibrium point under different scenario.

\begin{tabular}{|c|c|c|c|c|}
\hline & Actions & equilibrium volume of abated emission & Environmental cost, $\mathrm{EC}$ & $\begin{array}{l}\text { Marginal } \\
\text { environmental } \\
\text { cost' }\end{array}$ \\
\hline Option1 & $\begin{array}{l}\text { Adjust output } \\
\text { and actual } \\
\text { emission }\end{array}$ & $\begin{array}{l}\text { at } Q \text {,when Marginal income }=\text { marginal } \\
\text { abatement cost }\end{array}$ & $\mathrm{C}(\mathrm{Q})$ & $C^{\prime}(Q)$ \\
\hline Optioin2 & Sell permits & $\begin{array}{l}\text { at Qwhen marginal revenue of permits } \\
\text { sale }>\text { marginal abatement cost, and } \\
\mathrm{Q}^{\circ} \mathrm{Q}^{*}\end{array}$ & $\begin{array}{l}\mathrm{C}(\mathrm{Q})+\mathrm{T}\left(\mathrm{Q}-\mathrm{Q}^{*}\right)-\mathrm{P} 0(\mathrm{Q}- \\
\left.\mathrm{Q}^{*}\right)\end{array}$ & $\mathrm{P} 0-\mathrm{T}^{\prime}(\mathrm{X})$ \\
\hline \multirow[t]{3}{*}{ Option3 } & Sell permits & $\begin{array}{l}\text { At } \mathrm{Q} \text { when when marginal revenue of } \\
\text { permits sale }>\text { marginal abatement } \\
\text { cost, and } \mathrm{R}-\mathrm{R}_{0}<\mathrm{Q}_{1}{ }^{* *}\end{array}$ & $\begin{array}{l}\mathrm{C}\left(\mathrm{Q}_{1}{ }^{* *}\right)-\mathrm{P}_{0}\left(\mathrm{Q}_{1}{ }^{* *}-\mathrm{R}+\mathrm{R}_{0}\right) \\
+\mathrm{T}\left(\mathrm{Q}_{1}{ }^{* *}-\mathrm{R}+\mathrm{R}_{0}\right)\end{array}$ & $\mathrm{P}_{0}-\mathrm{T}^{\prime}(\mathrm{X})$ \\
\hline & $\begin{array}{l}\text { Emission } \\
\text { abatement }\end{array}$ & $\begin{array}{l}\text { When marginal income }\langle\text { marginal } \\
\text { abatement cos }\langle\text { marginal purchase } \\
\text { cost, and } \mathrm{Q}_{1}{ }^{* *}<\mathrm{R}-\mathrm{R}_{0}<\mathrm{Q}_{2}{ }^{* *}\end{array}$ & $\mathrm{C}(\Delta \mathrm{Q})$ & $\mathrm{C}^{\prime}(\mathrm{Q})$ \\
\hline & Buy permits & $\begin{array}{l}\text { When marginal purchase cost }\langle\text { marginal } \\
\text { abatement cost, } \mathrm{R}-\mathrm{R}_{0}>\mathrm{Q}_{2}{ }^{* *}\end{array}$ & $\begin{array}{l}\mathrm{C}\left(\mathrm{Q}_{2}{ }^{* *}\right)+\mathrm{P}_{0}\left(\mathrm{R}-\mathrm{R}_{0}-\mathrm{Q}_{2}{ }^{* *}\right) \\
+\mathrm{T}\left(\mathrm{R}-\mathrm{R}_{0}-\mathrm{Q}_{2}{ }^{* *}\right)\end{array}$ & $\mathrm{P}_{0}+\mathrm{T}^{\prime}(\mathrm{X})$ \\
\hline
\end{tabular}

\section{Conclusions}

Under the current design of the allowance trading system, emitters are given the flexibility to make decisions, which is based on the environmental cost, purchase cost, transaction cost and the fine when not comply with the regulation. Under conditions for option 1, reaction of the firm is determined by its own environmental cost, the system has little effect on it. So other alternatives should be introduce to force the emitter to reduce emission. When output is not adjustable, the emitter will choose option 2 or 3.The reaction of emitters will be influenced by the relationship between the purchase price of emitter and transaction cost, and the abatement cost. Reducing transaction cost will increase gains of the firms, pushing the volume of permit transactions. For the government, simplify the procedures of the system, increase transparency, reduce intervention in the market will help to push the market. Some efforts, such as favorable tax, or tax allowance, can also be made to help the firm to introduce innovation in technology, so to encourage reduction in emission. For emitters, introducing environmental costing system with better environmental cost will help them to make wise decisions.

\section{Acknowledgements}

This research was financially supported by the Canada China Scholarship Exchange Program (CCSEP).

\section{References}

[1] Dales John H:Pollution, Property, and Prices (University of Toronto Press, Toronto 1968)

[2] Montgomery, W. David: Markets in licenses and efficient pollution control programs, Journal of Economic Theory, Vol.5 (1972), pp. 395 - 418.

[3] Guo,X.M: On development of tradable permits in the power industry, energy procedia 5 (2011),pp.669-673.

[4] Information on http://www.gov.cn/zhengce/content/2014-08/25/content_9050.htm.

[5] Paul Leiby, Jonathan Rubin: Intertemporal permit trading for the control of greenhouse gas emissions, Environmental and Resource Economics , 19 (3) 2003 ,pp.229 - 256.

[6] Gangadharan.L: Transaction costs in pollution markets: an Empirical Study, Land Economics, Vol(4) 2000,pp. $601-614$.

[7] Zhang, Zhiyao,Peng Meng: Analysis on decisions of Firms under Tradable Allowance System,

Development and Economic of Technology information, (28)2008,pp.149 - 151. 